\title{
GWAS provides biological insights into mechanisms of the parasitic plant (Striga) resistance in sorghum
}

\author{
Jacinta Kavuluko', Magdaline Kibe ${ }^{1}$, Irine Sugut', Willy Kibet ${ }^{1}$, Joel Masanga', Sylvia Mutinda ${ }^{1,2}$, Mark Wamalwa',
} Titus Magomere ${ }^{1}$, Damaris Odeny ${ }^{3}$ and Steven Runo ${ }^{1 *}$ (D)

\begin{abstract}
Background: Sorghum yields in sub-Saharan Africa (SSA) are greatly reduced by parasitic plants of the genus Striga (witchweed). Vast global sorghum genetic diversity collections, as well as the availability of modern sequencing technologies, can be potentially harnessed to effectively manage the parasite.

Results: We used laboratory assays - rhizotrons to screen a global sorghum diversity panel to identify new sources of resistance to Striga; determine mechanisms of resistance, and elucidate genetic loci underlying the resistance using genome-wide association studies (GWAS). New Striga resistant sorghum determined by the number, size and biomass of parasite attachments were identified. Resistance was by; i) mechanical barriers that blocked parasite entry, ii) elicitation of a hypersensitive reaction that interfered with parasite development, and iii) the inability of the parasite to develop vascular connections with hosts. Resistance genes underpinning the resistance corresponded with the resistance mechanisms and included pleiotropic drug resistance proteins that transport resistance molecules; xylanase inhibitors involved in cell wall fortification and hormonal regulators of resistance response, Ethylene Response Factors.
\end{abstract}

Conclusions: Our findings are of fundamental importance to developing durable and broad-spectrum resistance against Striga and have far-reaching applications in many SSA countries where Striga threatens the livelihoods of millions of smallholder farmers that rely on sorghum as a food staple.

Keywords: Genome-wide association studies (GWAS), Parasitic plants, S. hermonthica (Striga), Striga resistance, Sorghum diversity panel

\section{Background}

Sorghum is a preferred staple cereal for millions of people in sub-Saharan Africa (SSA) but its production is greatly constrained by the root parasitic plant $S$. hermonthica Del. Benth.; This hemi-parasitic plant in the family Orobanchaceae attaches to roots of cereal crops, siphons their nutrients and may lead to death of the infected host. Yield losses due to Striga in Africa are

\footnotetext{
* Correspondence: runo.steve@ku.ac.ke

'Department of Biochemistry, Microbiology and Biotechnology, Kenyatta University, Nairobi, Kenya

Full list of author information is available at the end of the article
}

severe and range from 30 to $100 \%$ [1] translating to an estimated USD 7 billion every year [2].

Striga control methods are limited. These include cultural and agronomic practices [3], seed treatment with herbicides [4], use of trap crops [5] and deployment of resistant varieties [6, 7]. Although these strategies have been used for a long time, they are either ineffective or poorly adaptable by African smallholder farmers [8]. Striga resistance breeding is a viable management strategy [9]. However, resistance can be short-lived and overcome by the parasite [2]. An effective resistance breeding approach will be one that combines several

(c) The Author(s). 2021 Open Access This article is licensed under a Creative Commons Attribution 4.0 International License, which permits use, sharing, adaptation, distribution and reproduction in any medium or format, as long as you give appropriate credit to the original author(s) and the source, provide a link to the Creative Commons licence, and indicate if changes were made. The images or other third party material in this article are included in the article's Creative Commons licence, unless indicated otherwise in a credit line to the material. If material is not included in the article's Creative Commons licence and your intended use is not permitted by statutory regulation or exceeds the permitted use, you will need to obtain permission directly from the copyright holder. To view a copy of this licence, visit http://creativecommons.org/licenses/by/4.0/ The Creative Commons Public Domain Dedication waiver (http://creativecommons.org/publicdomain/zero/1.0/) applies to the data made available in this article, unless otherwise stated in a credit line to the data. 
sources of resistance (pyramiding) but realizing such control is limited by availability of well characterised sources of resistance [10].

In characterizing Striga resistance sources, it is important to firstly, delineate the various mechanisms used by hosts to fight against the parasite. Broadly, these occur at two levels; (i) pre-attachment, which includes resistance mechanisms that hinder parasite germination and haustorium development [11-14] and, (ii) post-attachment, resistance mechanisms that hinder parasite attachment and growth inside host tissue - such as mechanical barriers [15], secondary metabolites [16], and hypersensitive reactions [17]. Upon determination of the causes, genetic loci underpinning such mechanisms can then be mapped. In sorghum, earlier Striga resistance loci mapping studies used quantitative trail loci (QTL) analysis based on simple sequence repeat and amplified fragment length polymorphism (AFLP) markers in two recombinant inbred line (RIL) populations derived from crosses between; (i) post-attachment resistant cultivar N13 and the susceptible cultivar E36-1 (ii) pre-attachment resistant IS9830 crossed to the susceptible cultivar E36-1 [18]. Subsequent studies have used genotyping by sequencing (GBS)-based single nucleotide polymorphisms (SNPs) in genome wide association studies (GWAS) to determine genomic regions of sorghum associated with adaptation to Striga [19]. Although these studies have provided insights to genetic/genomic regions linked to Striga resistance in sorghum, interpreting field GWAS studies is confounded by environmental variability that sometimes complicate interpretation of association data [18]. Moreover, it has not been possible to determine genetic mechanisms specifically responsible for postattachment Striga resistance.

Here, we evaluated the hypothesis that genetic mechanisms underpinning specific post-attachment Striga resistance in sorghum can be resolved by GWAS and that confounding environmental variability can be lessened by carrying out Striga resistance assays under controlled greenhouse conditions. We determined the post-attachment resistance responses of sorghum accessions derived from a large diversity panel using rhizotron assays. To home in on genomic regions associated with Striga resistance at high resolution, we used GBS-based SNPs. Together, these analysis led us to unravel various genetic mechanisms that sorghum uses to battle Striga parasitism.

\section{Results}

The sorghum diversity panel is genetically structured according to races and geographical origin

The sorghum diversity panel constituted all major cultivated, wild and intermediate races. Distribution of these genotypes was across Africa, India, the Middle East, Europe and North America. Information on the geographical origin, general races, and population structure is outlined in Fig. 1; Fig. S1; Table S1. Caudatum and its intermediate races represented the most common genotypes in the panel $(40.54 \%)$ and were found distributed across all continents. A majority of them were from Africa (East, West and Central), and clustered based on their geographic origin (Fig. 1B,C; Table S1). Kafir genotypes were mostly distributed in Southern Africa, their centre of origin. Bicolor was found in diverse geographical locations in Africa (East, South and West Africa), North America, East Asia (China), India and the Mediterranean region (Fig. 1A). Durra was mostly distributed in the Indian subcontinent and Eastern Africa, although Central Africa also showed a few Durra and the sub-race Durra muskwaari (Dmkr). Furthermore, intermediate race Durra-caudatum (DC) was predominant in India but also well represented in East Africa and the Middle East. Wild sorghum genotypes of subspecies arundinaceum, drummondii were distributed in West Africa but also present in West Africa was the sub-race Guinea margaritiferum (Gma). Finally, the wild subspecies verticilliflorum were from South Africa and North America (Fig. 1C).

ADMIXTURE and NJ (Neighbour Joining) analysis were effective in differentiating the sorghum genotypes. In ADMIXTURE, a cross-validation approach revealed that the most probable $K$ ranged from 6 to 9 with $K=7$ having the lowest CV (Cross Validation) error. This analysis led to 5 major clusters of genotypes with minor overlaps. Overall, differentiation was according to the race structures rather than geographic origins of sorghum genotypes and comprised Guinea sub-races, Kafir, Durra, Guinea and Caudatum. Although NJ was comparable to ADMIXTURE in differentiating the genotypes, it was not possible to get a distinct Caudatum cluster. Instead, we obtained clusters of Guinea, Kafir, Durra, and Guinea sub-races (Fig. 1C).

Further characterization of the population structure using principal components (PC), showed that PC1, PC2, and PC3 explained the highest proportion of the total variance. A PCA plot (Fig. S1) produced using these PCs affirmed the stratification of the sorghum diversity panel earlier described in ADMIXTURE and NJ. A total of five distinct clusters were generated with the most variant sub group consisting of Kafir (PC1), Guinea -Caudatum and Caudatums (PC2) and sub-race Guinea margaritiferum on PC3.

\section{Sorghum genotypes in the diversity panel exhibit different levels of post-germination resistance against $S$. hermonthica}

Resistance response of sorghum accessions as determined using the rhizotron assay provided three metrics for measuring the levels of resistance: Mean number 


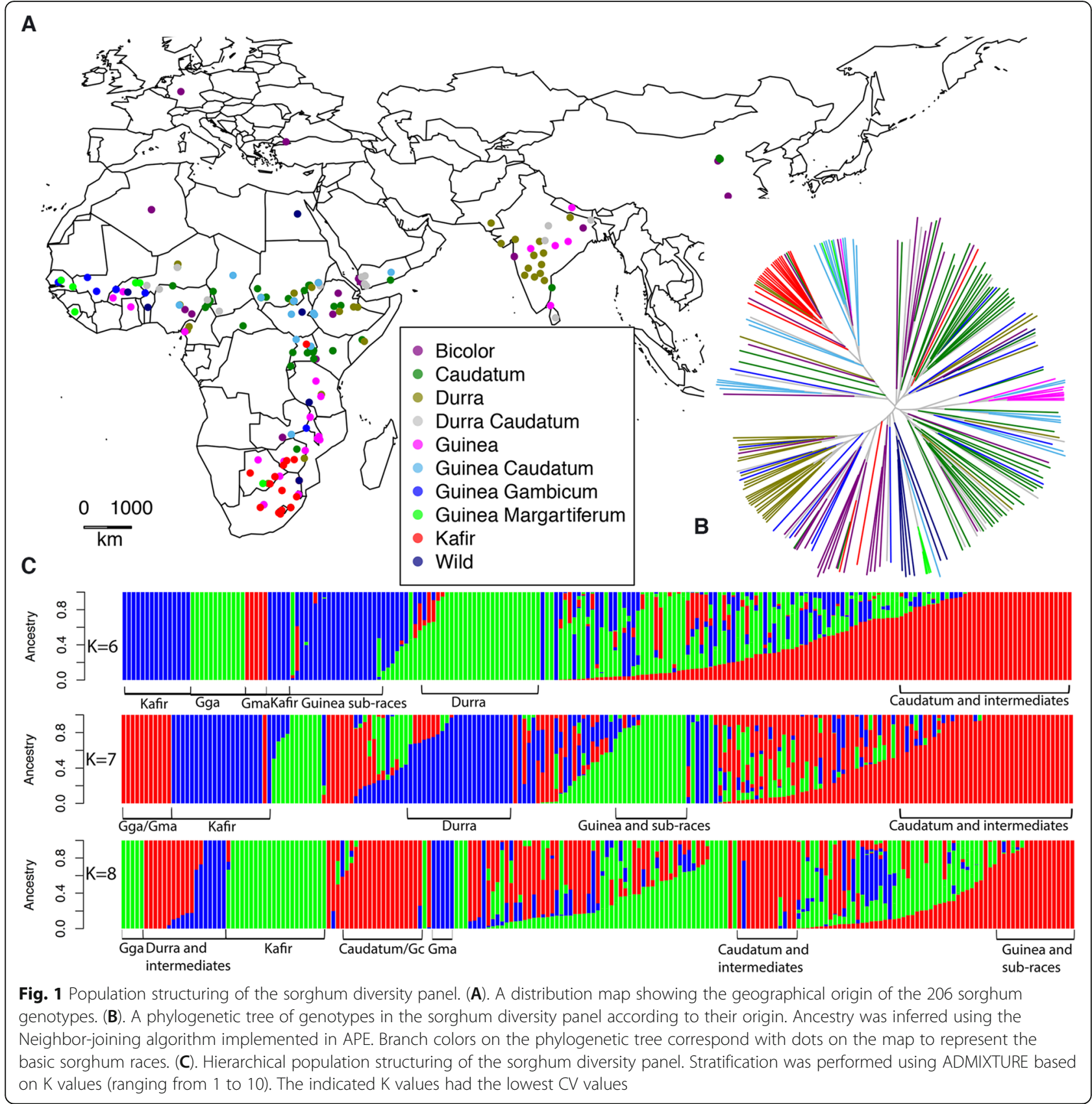

of Striga attachments, mean Striga length and mean Striga biomass. Various resistance responses based on numbers and sizes of Striga seedlings attached on representative host roots are shown in Fig. 2. Resistant genotypes such as IS9830 and IS14963 (Fig. 2A,B) supported few, and short parasite seedlings with low Striga biomass while susceptible responses for example IS20016 and IS16396 (Fig. 2C,D) showed successful parasite colonization marked by numerous and long Striga plants with a large biomass.
Responses were categorized as; "Highly Resistant", "Resistant", "Moderately Resistant", "Susceptible" and "Highly Susceptible" based on comparisons with the resistant controls (N13 and IS9830) and the susceptible check (Ochuti). Proportions for different categories of resistance as determined by number of Striga attachments, Striga length and Striga biomass are presented in Figs. S2A, B and C respectively. Resistance proportions by mean number of Striga attachments were as follows: "Highly Resistant" $=6.8 \%$, "Resistant" $=27.1 \%$ "Moderately Resistant" $=14.6 \%$, 


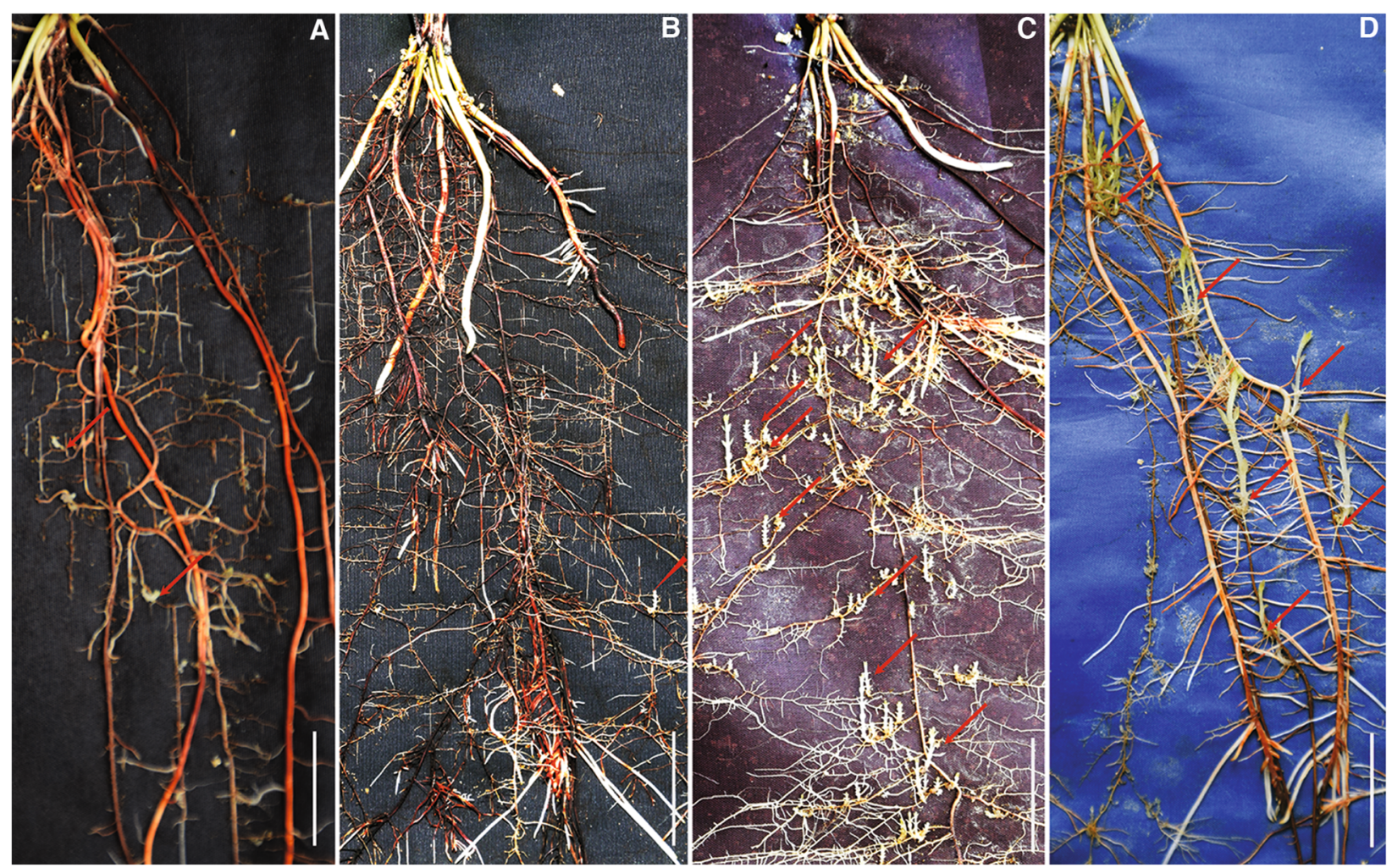

Fig. 2 Resistance response of sorghum genotypes to S. hermonthica infection on rhizotrons at 21 DAl. (A) and (B) Resistant phenotypes exhibited by IS9830 and IS14963, respectively. The genotypes have short and few parasite attachments. (C) and (D) Susceptible phenotypes represented by IS20016 and IS16396, respectively. The genotypes have numerous and long attachments. Arrows indicate parasite attachments on host roots. Bar = $2 \mathrm{~cm}$

"Susceptible" $=18 \%$ and "Highly Susceptible" $=33.4 \%$ while proportions of resistance measured by mean Striga length were as "Highly Resistant" $=2.9 \%$, "Resistant" $=6.8 \%$, "Moderately Resistant" $=12.1 \%$, "Susceptible" $=12.6 \%$ and "Highly Susceptible" $=65.5 \%$. And resistance proportions determined using mean Striga biomass were as follows: "Highly Resistant" = $18 \%$, "Resistant" $=27.7 \%$, "Moderately Resistant", "Resistant" $=20.9 \%$, "Susceptible" $=11.1 \%$ and "Highly Susceptible" $=22.8 \%$. To better understand the metric that contributed the most to overall variation in resistance among the sorghum genotypes, the 3 metrics were subjected to PC analysis (Fig. S2). Results showed that number of Striga attachments and Striga biomass accounted for most $(89.0 \%)$ of the total variance distributed. Particularly, number of Striga attachments accounted for $61.2 \%$, while Striga biomass and Striga length accounted for 27.8 and $11.0 \%$ of the variance, respectively (Fig. S2D).

Next, we considered individual resistance responses of the sorghum accessions. These results are presented in Table S2. Additionally, Fig. 3 is a representation of the 50 best performing accessions as determined by number of Striga attachments (Fig. 3Aa), Striga length (Fig. 3Ab) and Striga biomass (Fig. 3Ac).
Striga resistance, as measured by number of seedlings attached on sorghum genotypes, ranged from $41.00 \pm$ 0.53 in the most resistant genotype (IS41724), to $292.70 \pm 0.26$ for the most susceptible (IS20016), a Guinea gambicum landrace from West Africa. Noteworthy, IS41724 and IS14478, a wild drummondii from East Africa had significantly lower number of attachments than either of the resistant controls IS9830, (number of attachments $=58.27 \pm 0.61$ ) and N13, (number of attachments $=57.67 \pm 1.10$ ). Ten other genotypes were categorized as highly resistant because the number of attachments on their roots were not significantly different from those of IS9830. By this metric, the susceptible check Ochuti (number of attachments $=116.60 \pm 0.79$ ) was categorized as "Highly Susceptible".

Based on Striga mean length, the most resistant genotype was again IS9830 (mean length of Striga attachments $=0.47 \pm 0.08 \mathrm{~mm}$ ), while the most susceptible one was IS9168 a Kenyan Bicolor landrace (mean length of attachments $=72.96 \pm 0.70 \mathrm{~mm}$ ). The length of IS9830 was not significantly different from 15 other sorghum genotype and these formed the "Highly Resistant" category. N13, supported relatively larger seedlings $(15.72 \pm 0.19 \mathrm{~mm})$ and fell into the category of "Moderately Resistant". In comparison, the susceptible check 


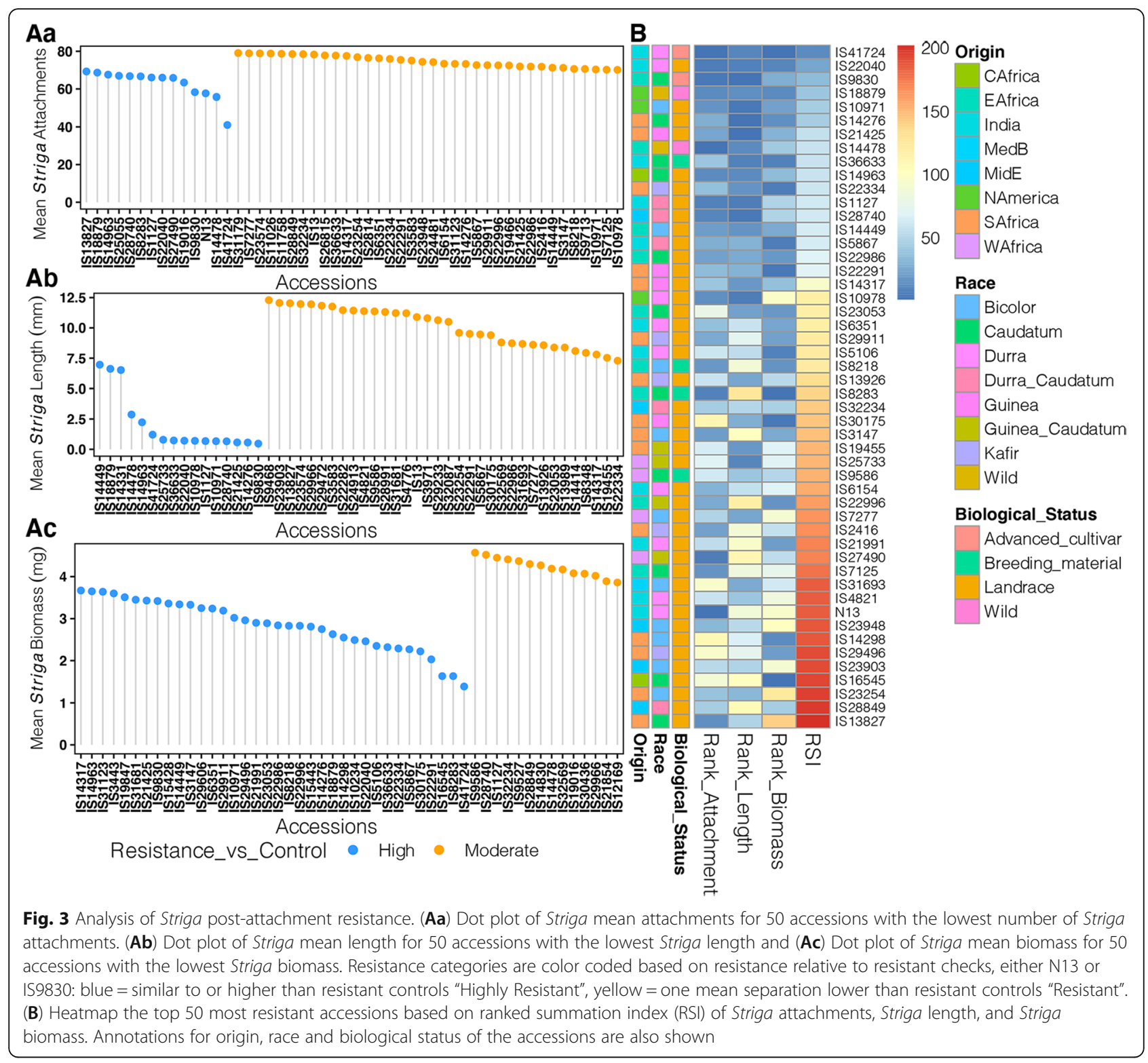

Ochuti had seedlings measuring $47.93 \pm 0.58 \mathrm{~mm}$ and was categorized as "Highly Susceptible".

With regard to mean weight of Striga, resistance ranged from $1.39 \pm 0.04 \mathrm{lmg}$ in IS41724 to $32.97 \pm 0.22$ $\mathrm{mg}$ in SSM276, which is a landrace of a Guinea margaritiferum sub-race from Burkina Faso. The biomass of the most resistant genotypes (IS41724) was statistically similar to that of IS9830 (mean Striga biomass $=3.42 \pm 0.12$ $\mathrm{mg}$ ) and 34 other genotypes. "The Highly Susceptible" category had 46 genotypes which also included the susceptible control, Ochuti, had a mean biomass of $11.77 \pm$ $0.77 \mathrm{mg}$.

In general, genotypes with short seedlings also had few attachments and therefore a correspondingly low biomass. However, in some genotypes, the Striga mean length was low but the attachments were numerous leading to a large biomass. For example, IS22239 was placed in the "Highly Susceptible" category using number of attachments $(205.73 \pm 14.88)$ but in the "Resistant" category using mean Striga length $(12.31 \pm 2.70 \mathrm{~mm})$. Its biomass was $28.03 \pm 1.17 \mathrm{mg}$ which was in the "Highly Susceptible" category. In other cases, genotypes had long but few attachments. For example, the genotype N13 had relatively long $(15.72 \pm 0.19 \mathrm{~mm})$ but few $(57.67 \pm$ 1.10) attachments and consequently a moderate biomass (6.33 $\pm 0.11 \mathrm{mg})$.

The Rank Summation Index (RSI) [11, 20] was computed to determine the combined resistance responses as measured by Striga attachments, Striga length and Striga biomass. These results are presented in Fig. 3B as 
a heatmap for the top 50 accessions and in Table S3. Further, a list of the top 10 resistant accessions is presented in Table 1. Among the genotypes only IS9830 had previously been reported as resistant [18]. To our knowledge, the resistance of the other 9 genotypes have never been described and form a new genetic resource for Striga resistance improvement in sorghum. We would like to highlight two genotypes because of their advanced breeding status and therefore high potential for immediate integration in Striga resistance programs in SSA. Firstly, the genotype IS41724, an advanced Indian Durra breeding line which ranked highest with regard to fewest number of Striga attachments $(41.00 \pm$ $0.53)$; least Striga length $(1.21 \pm 0.10 \mathrm{~mm})$ and least Striga biomass $(1.39 \pm 0.04 \mathrm{mg})$ and secondly, IS36633 also an Indian breeding germplasm of the Caudatum race with resistance metrics of Striga attachments $(77.73 \pm 1.21)$ Striga length $(0.73 \pm 0.04 \mathrm{~mm})$ Striga biomass $(2.32 \pm 0.17 \mathrm{mg})$. Also noteworthy, in this list of resistant genotypes are two wild sorghum accessions IS18879, a wild Arundinaceum from USA with metrics of resistance as follows: Striga attachments, (68.67 \pm 1.45$)$ Striga length $(6.62 \pm 0.44 \mathrm{~mm})$ and Striga biomass $(2.63 \pm$ $0.09 \mathrm{~mm}$ ) and IS14478, a wild Drummondii from Sudan with resistance metrics as follows: Striga attachments (55.80 \pm 3.29$)$, Striga length $(2.87 \pm 1.34 \mathrm{~mm})$, and Striga biomass $(4.19 \pm 0.08 \mathrm{mg})$. The remaining genotypes were landraces sourced from Malawi (IS21425); USA; (IS10971) and India (IS22040) and South Africa (IS14276).

\section{Sorghum genotypes exhibit diverse mechanisms of resistance against $S$. hermonthica}

Interactions between various sorghum hosts and $S$. hermonthica, are represented as close-up images between individual Striga seedlings attached to sorghum roots at 9 days after infection (DAI) as well as transverse sections through such haustoria (Fig. 4).
In susceptible interactions, the parasite was able to penetrate host cells and connect its vascular tissue (xylem) to that of the host to form a conduit for transfer of water and nutrients. This is the hallmark of a welldeveloped haustorium and subsequent proliferation of vegetative tissue, and starts with the bursting of the seed coat. This phenomenon was demonstrated in the interaction between IS18829 and S. hermonthica, in which we observed a well-formed haustorium with clear vascular connections between host and the parasite (Fig. 4Aa). In addition, the parasite grew rapidly and formed the five scale leaves - typical of susceptible interactions at this stage of development. A transverse section through the point of attachment indicated complete parasitic penetration of host endodermis, formation of clear xylem-to-xylem connections, as well as development of a hyaline body; a vital storage tissue for the parasite (Fig. 4Ab).

In contrast, resistant genotypes blocked parasite development at various levels by diverse mechanisms. We observed the following resistance responses; i) mechanical barrier-like that blocked parasite entry into host tissue; ii) hypersensitive reaction (HR) at the host-parasite interface, and iii) inability of the parasite to form vascular connections with the host.

\section{Resistance due to mechanical barriers}

In N13, parasite development was blocked before it entered the host cortex. The haustorium did not develop fully and a majority of infecting parasites did not proceed to form vegetative tissue (Fig. 4Ba). Histological analysis showed that the parasite was poorly developed (Fig. $4 \mathrm{Bb}$ ). In total, $50 \%$ of sectioned tissue (i.e. 5 out of 10 blocks sectioned) showed this phenotype. In genotype IS1097810978, the parasite was able to penetrate the host cortex, but failed to breach the endodermis (Fig. $4 \mathrm{Ca}, \mathrm{Cb}$ ). Histological sections showed a parasite that went round the host pericycle instead of penetrating

Table 1 The 10 most resistant accessions based on all metrics of attachments, length and biomass as determined by the Rank Summation Index (RSI) method

\begin{tabular}{|c|c|c|c|c|c|c|c|}
\hline RSI rank & Genotype & Attachments & Length (mm) & Biomass (mg) & Biological status & Race & Country of origin \\
\hline 1. & IS41724 & $41.00 \pm 0.53$ & $1.21 \pm 0.10$ & $1.39 \pm 0.04$ & Advanced cultivar & Durra & India \\
\hline 2. & IS22040 & $66.00 \pm 1.11$ & $0.71 \pm 0.03$ & $2.46 \pm 0.11$ & Landrace & Durra & India \\
\hline 3. & IS9830 & $58.27 \pm 0.61$ & $0.47 \pm 0.08$ & $3.42 \pm 0.12$ & Advanced cultivar & Caudatum & Sudan \\
\hline 4. & IS18879 & $68.67 \pm 1.45$ & $6.62 \pm 0.44$ & $2.63 \pm 0.09$ & wild & Arundinaceum & USA \\
\hline 5. & IS10971 & $70.33 \pm 0.81$ & $0.67 \pm 0.14$ & $3.02 \pm 0.11$ & Landrace & Bicolor & USA \\
\hline 6. & IS14276 & $73.27 \pm 0.83$ & $0.56 \pm 0.14$ & $2.75 \pm 0.24$ & Landrace & Caudatum & South Africa \\
\hline 7. & IS21425 & $71.93 \pm 1.15$ & $0.57 \pm 0.01$ & $3.43 \pm 0.09$ & Landrace & Guinea & Malawi \\
\hline 8. & IS14478 & $55.80 \pm 3.29$ & $2.87 \pm 1.34$ & $4.19 \pm 0.08$ & wild & Drummondii & Sudan \\
\hline 9. & IS36633 & $77.73 \pm 1.21$ & $0.73 \pm 0.04$ & $2.32 \pm 0.17$ & Breeding material & Caudatum & India \\
\hline 10. & IS14963 & $67.6 \pm 0.8$ & $2.23 \pm 0.08$ & $3.65 \pm 0.17$ & Landrace & Caudatum & Cameroon \\
\hline
\end{tabular}



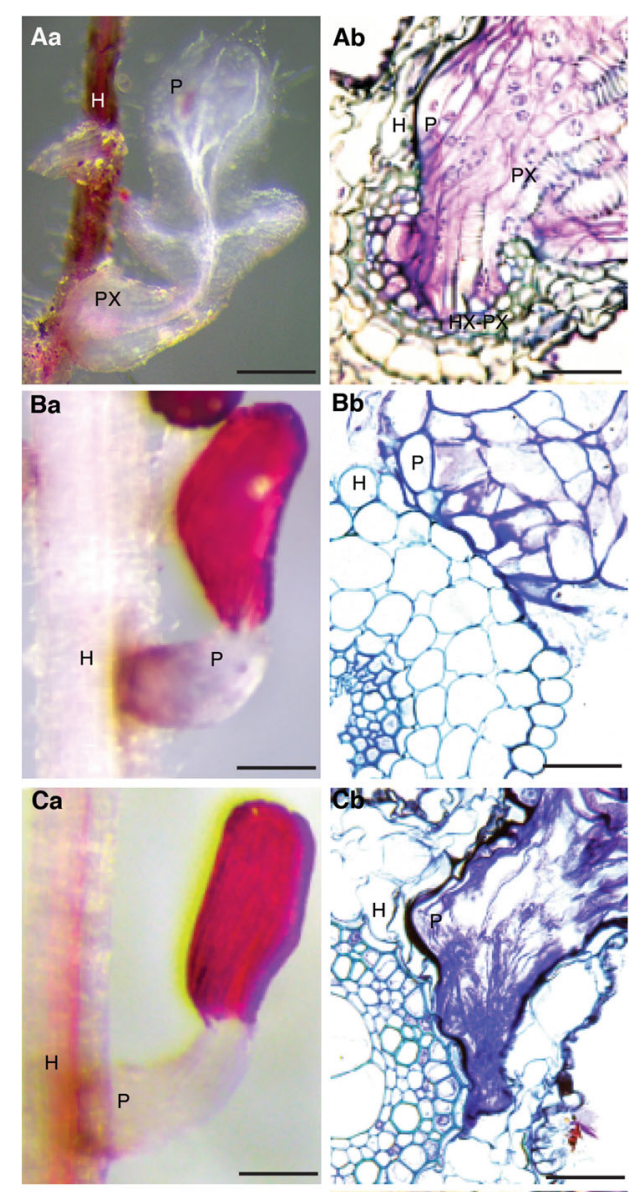

Da
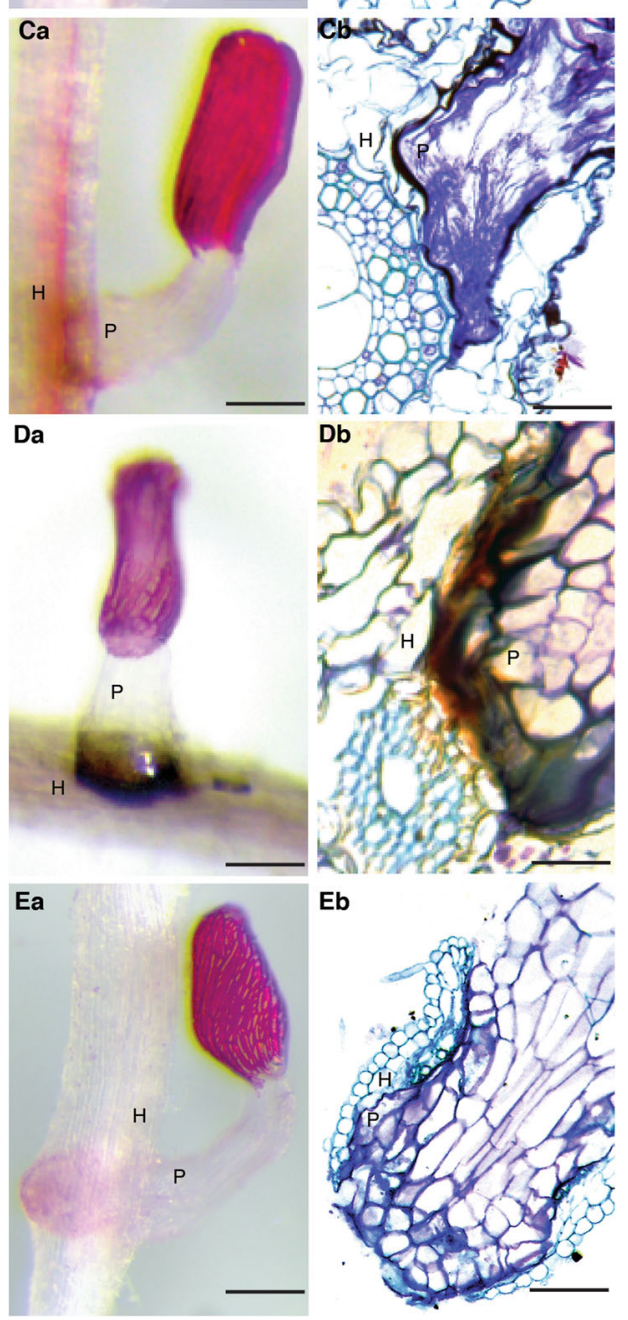

Eb
Fig. 4 Resistance mechanisms of sorghum to S. hermonthica 9 DAl. (Aa) Colonization of IS18829 showing a well-established haustorium at the point of attachment. The parasite is also fully vegetative and established vascular connections with the host. Scale $=0.5 \mathrm{~cm}$. (Ab) Transverse section through IS18829 showing penetration of the root cortex and endodermis. Penetration resulted in vascular connection between the host and parasite xylem. Scale $=0.1 \mathrm{~mm}$. $\mathrm{H}=$ host

$P=$ parasite, $\mathrm{Hx}=$ host $x y l e m, \mathrm{Px}=$ parasite $x y l e m, \mathrm{Hx}-\mathrm{Px}=$ host $\mathrm{xylem}$ connected to parasite xylem. (Aa) Colonization of N13 by Striga showing a poorly established parasite with a darkly stained haustorium, possible because of dead cells. Scale $=1 \mathrm{~mm}$. (Bb) Transverse section through N13 tissue showing failure of the parasite to breach the host's cortex. Scale $=0.1 \mathrm{~mm}$. (Ca)

Colonization of IS1097810978 showing a poorly developed parasite without vascular connection. Scale $=1 \mathrm{~mm}$. (Cb) A transverse section through an embedded IS1097810978 root tissue showing successful penetration of the cortex but parasite blockage at the endodermis. Scale $=0.1 \mathrm{~mm}$. (Da) Colonization of IS14963 showing an intense Hypersensitive Reaction (HR) at the site of parasite infection. Scale = $1 \mathrm{~mm}$. (Db) A transverse section through an embedded IS14963 root tissue showing blockage of the parasite tissue due to $\mathrm{HR}$ at the host-parasite interphase. Scale $=0.1 \mathrm{~mm}$. (Ea) Colonization of IS9830 showing the parasite penetrating host tissue but failing to establish vascular connections. The parasite instead emerges on the opposite side of the root. Scale $=1 \mathrm{~mm}$. (Eb) A transverse section through an embedded tissue of IS9830 showing parasite penetration of the host root and subsequent emergence in the opposite

direction. Scale $=0.1 \mathrm{~mm}$

it (Fig. $4 \mathrm{Cb}$ ). This resistance is suggestive of cell wall fortification or lignin deposition. The frequency of this phenotype, as determined by histological analysis, was $40 \%$ (i.e. 4 out of 10 blocks sectioned).

\section{Resistance due to hypersensitive reaction}

IS14963 mounted a resistance response against Striga characterized by an intense hypersensitive reaction at the host-parasite interface (Fig. $4 \mathrm{Da}, \mathrm{Db}$ ). In this genotype, a majority of seedlings $(90 \% ; n=10)$ failed to successfully penetrate the host tissue and did not form vascular connections. Consequently, vegetative tissue failed to develop with only an intact seed coat seen during the screening period (Fig. 4Da). A section through the haustorium of IS14963 further showed clear inhibition of the parasite at the host endodermis due to necrosis (Fig. 4Db).

\section{Resistance due to inability of the parasite to differentiate and form vascular connections}

In the highly resistant IS9830, we observed a resistance response that occurred because the parasite was unable to differentiate and form vascular connections with the host (Fig. 4Ea, Eb). In this resistance response, the parasite attached, grew past the cortex, endodermis and emerged at the opposite end without attempting to form vascular connections with the host (Fig. 4Ea). Histological analysis confirmed failure of the parasite to 
differentiate and form connections with the host in most tissues $(60 \% ; n=10)$ sectioned (Fig. 4Ea).

\section{GWAS identifies genetic loci associated with $S$. hermonthica in sorghum}

Fixed and random model Circulating Probability Unification (FarmCPU) model analysis of the sorghum diversity panel led to identification of candidate genetic regions associated with Striga resistance. These data are presented as Manhattan plots in Fig. 5. Suitability of the Farm CPU model for our analysis is shown using Quantile-Quantile (QQ) plots in Fig. 5. Overall, genetic causes of Striga resistance could be linked to observed or previously described resistance phenotypes. We found significantly associated SNPs on genes involved in the following functions: i) secretion of defense molecules, ii) modification of the host cell wall or, iii) activation of sorghum's pathogen-mediated resistance genes. These results are summarized in Table 2.

Significant associations of Striga resistance with a pleiotropic drug resistance (PDR)/ ATP Binding Cassette $(\mathrm{ABC})$ class $\mathrm{G}$ transporter at position S2_69292723 ( $p=$ (5.29E-05) as well as an Isoflavon reductase (IFR) at S3 58064948 ( $p=4.00 \mathrm{E}-03)$ point to the importance of synthesis and secretion of secondary metabolites in defense. $\mathrm{ABC}$ transporters have a cytosolic nucleotide binding domain that bind ATP and a hydrolysis hydrophobic transmembrane domain that translocate pathogen defense molecules while IFR is involved in the biosynthetic pathway of isoflavonoid phytoalexin. Interestingly, PDR transporters are known to bind and secrete phytoalexins.

We detected the Fasciclin-like arabinogalactan protein 11 that regulates plasticity and integrity of cell walls at position S9_5732771 ( $p=1.80 \mathrm{E}-03)$. In addition, we found secondary cell wall modification genes for lignin

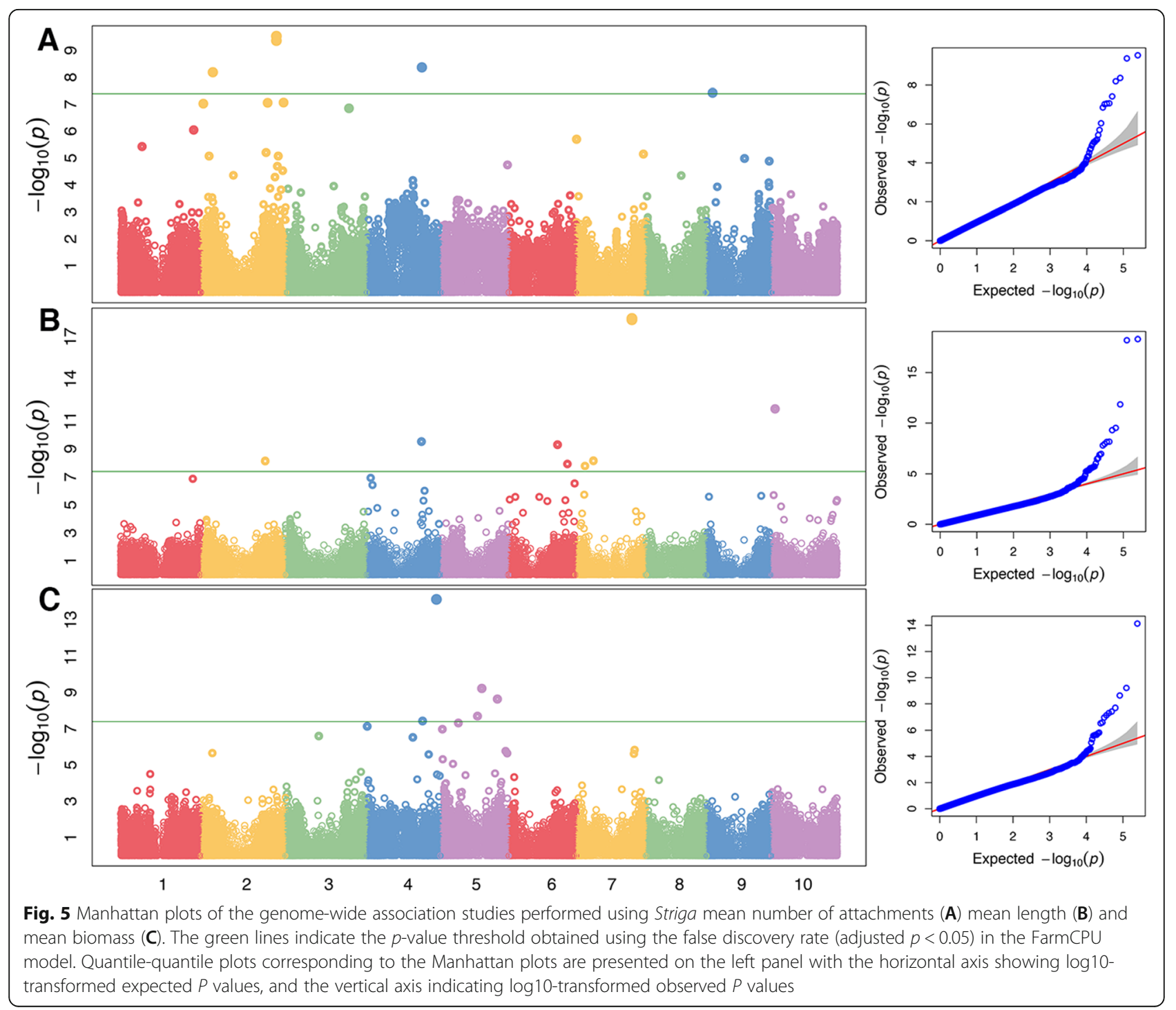


Table 2 Sorghum SNPs showing significant genome-wide associations with S. hermonthica resistance determined using traits of mean number of attachments, mean length and mean biomass (FDR correction at $\propto 0.05$ ). SNPs within genes are presented with their annotations in order of chromosomal location. AF: allele frequency; AdjP: P-value after FDR adjustment. * ${ }^{*}$ present SNPs common to QTL detected in Haussmann et al., 2004). Letters after SNP positions represent trait to detect the SNP: a = attachment, $\mathrm{b}=$ length, $\mathrm{c}=$ biomass

\begin{tabular}{|c|c|c|c|c|c|}
\hline Chr & Position & $\mathrm{AF}$ & AdjP & Gene ID & Annotation \\
\hline 1 & $66423166 c^{*}$ & 0.25 & 3.03E-03 & Sobic.001G375900 & Hypothetical protein \\
\hline 1 & $66995004 a^{*}$ & 0.38 & $2.20 \mathrm{E}-02$ & Sobic.001G382000 & Serine/threonine-protein kinase AtPK19 \\
\hline 2 & $1990072 a^{*}$ & 0.5 & $3.00 \mathrm{E}-03$ & Sobic.002G021700 & F-box proteins \\
\hline 2 & $10791041 a^{*}$ & 0.17 & 3.99E-04 & N/A & N/A \\
\hline 2 & $61226505 a^{*}$ & 0.18 & $2.90 \mathrm{E}-03$ & Sobic.002G220700 & Uncharacterized protein \\
\hline 2 & $75881569 a^{*}$ & 0.14 & $2.90 \mathrm{E}-03$ & N/A & N/A \\
\hline 2 & $69292723 a^{*}$ & 0.17 & $5.29 \mathrm{E}-05$ & Sobic.002G321300 & ABCG transporter \\
\hline 2 & $59157949 b^{*}$ & 0.46 & $2.52 \mathrm{E}-04$ & Sobic.002G201600 & PMT2 Methyltransferase \\
\hline 3 & $58064948 a$ & 0.13 & 4.00E-03 & Sobic.003G241300 & Isoflavon reductase \\
\hline 4 & $3830076 b$ & 0.09 & 2.83E-03 & obic.004G047001 & NA \\
\hline 4 & $50695987 a$ & 0.31 & 4.00E-04 & N/A & Ethylene responsive element binding factor 4 \\
\hline 4 & $52466133 b$ & 0.45 & $5.12 \mathrm{E}-02$ & N/A & Uncharacterized protein \\
\hline 4 & $64068558 c$ & 0.1 & $2.00 \mathrm{E}-05$ & Sobic.004G020200 & Cytosine-5- -Methyltransferase 3-Related \\
\hline 4 & $51292838 c$ & 0.14 & $1.84 \mathrm{E}-03$ & Sobic.004G163700 & N/A \\
\hline 4 & $53412080 b$ & 0.43 & $1.69 \mathrm{E}-02$ & Sobic.004G181500 & DNA repair protein \\
\hline 4 & $438979 c$ & 0.43 & 2.57E-03 & Sobic.004G005100 & Zinc finger with peptidase domain protein \\
\hline 4 & $5610661 b$ & 0.13 & $6.98 \mathrm{E}-03$ & Sobic.004G068800 & N/A \\
\hline 4 & $50512606 b$ & 0.17 & $1.89 \mathrm{E}-05$ & Sobic.004G158901 & Ethylene-responsive transcription factor ERF113 \\
\hline 5 & $1591316 c$ & 0.12 & $3.28 \mathrm{E}-03$ & Sobic.005G017700 & Hypothetical protein \\
\hline 5 & $33845800 c$ & 0.07 & $1.00 \mathrm{E}-03$ & N/A & N/A \\
\hline 5 & $37742821 c$ & 0.06 & $7.48 \mathrm{E}-05$ & $\mathrm{~N} / \mathrm{A}$ & N/A \\
\hline 5 & $52091605 c$ & 0.13 & $1.92 \mathrm{E}-04$ & N/A & N/A \\
\hline 5 & $16194394 c$ & 0.27 & $1.96 \mathrm{E}-03$ & Sobic.005G099000 & Xylanase inhibitor 1 \\
\hline 6 & $6412692 b$ & 0.25 & $3.31 \mathrm{E}-02$ & N/A & N/A \\
\hline 6 & $28486530 b$ & 0.38 & 3.31E-02 & $\mathrm{N} / \mathrm{A}$ & N/A \\
\hline 6 & $35866190 b$ & 0.48 & 5.20E-02 & N/A & N/A \\
\hline 6 & $45280156 b$ & 0.16 & 2.46E-05 & N/A & Hypothetical protein \\
\hline 6 & $52535510 b$ & 0.24 & 4.94E-02 & N/A & N/A \\
\hline 6 & $60968111 b$ & 0.29 & 5.85E-03 & N/A & Secondary wall NAC transcription factor 4 \\
\hline 6 & $1389246 b$ & 0.33 & 4.90E-02 & Sobic.006G009400 & Peroxiredoxin1 (Prx1) \\
\hline 6 & $54417370 b$ & 0.2 & 3.54E-04 & Sobic.006G190000 & Downy mildew resistant 6 (DMR6) \\
\hline 7 & $413066 a$ & 0.12 & 4.40E-02 & Sobic.007G004500 & HSP60 \\
\hline 7 & $7777464 b$ & 0.24 & 2.99E-02 & Sobic.007G070000 & Uncharacterized protein \\
\hline 7 & $8351776 b$ & 0.22 & 4.50E-04 & N/A & N/A \\
\hline 7 & $16156498 b$ & 0.08 & $2.52 \mathrm{E}-04$ & N/A & N/A \\
\hline 7 & $51452375 b$ & 0.13 & 7.49E-14 & N/A & N/A \\
\hline 7 & $51462880 b$ & 0.18 & 7.49E-14 & N/A & N/A \\
\hline 9 & $5732771 a^{*}$ & 0.39 & $1.80 \mathrm{E}-03$ & Sobic.009G056400 & Fasciclin-like arabinogalactan protein 11 \\
\hline 10 & $2576197 b$ & 0.19 & $3.02 \mathrm{E}-02$ & Sobic.010G032000 & Early nodulin 93 \\
\hline 10 & $3821956 b^{*}$ & 0.07 & 1.15E-07 & Sobic.010G049100 & Acyl coa oxidase 1 \\
\hline
\end{tabular}


biosynthesis genes: i) PMT2 Methyltransferase at S2 $59157949(p=2.52 \mathrm{E}-04)$, ii) Secondary wall NAC transcription factor 4 at S6_60968111 ( $p=5.85 \mathrm{E}-03)$ and, iii) Early nodulin 93 at S10_2576197 (3.02E-02). Finally, we detected significant associations at S5_16194394 ( $p=$ 1.96E-03) with Xylanase inhibitor 1 that possibly functions to inhibit Striga's xylanases.

Our GWAS also revealed association with the Ethylene-responsive transcription factor ERF113 at S4 50512606 (1.89E-05). ERF113 is a key regulator of both jasmonic acid (JA) as well as salicylic acid (SA) mediated defense pathways in plants. In addition, Peroxisomal acyl-CoA oxidase 1 detected at S10_3821956 ( $p=1.15 \mathrm{E}$ 07 ) is a key enzyme in JA biosynthesis. Downstream of defense pathway, we detected the Downy mildew resistance 6 (DMR6) at position S6_54417370b $(p=3.54 \mathrm{E}-04)$ and the hypersensitive reaction (HR) associated Peroxiredoxin1 (Prx1) at S6_1389246 ( $p=4.90 \mathrm{E}-02)$. Other genes that could also putatively have a role in the innate defense pathway were a zinc finger with peptidase domain identified at S4_438979 $(p=2.57 \mathrm{E}-03)$ and Heat shock protein 60 (HSP60) at S7_413,066 ( $p=4.40 \mathrm{E}-02)$.

The rest of the significant SNPs occurred on noncoding regions, or on genetic regions where the gene's annotated function could not be related to pathogen resistance (Table 2).

\section{Discussion}

Our goal was to develop a technology platform for effectively exploiting the genetic diversity of sorghum for resistance against Striga, a parasitic plant that greatly limits cereal production in most parts of sub-Saharan Africa. We first screened a large collection of diverse sorghum genotypes, using an efficient high-throughput Striga screening method based on soil-free root observation chambers called rhizotrons, in order to identify new sources of Striga resistance. Secondly, we characterized the mechanisms of such resistance, using detailed microscopic and histological analyses following Striga infection, exhibited by the sorghum genotypes. Finally, we determined the underlying genetic factors related to the resistance displayed by various sorghum genotypes using GWAS. The diversity panel provided a good resource for resistance screening and GWAS. It is reasonable to assume that variations could exist between genotyped and phenotype accessions - even with the high degree of self-fertilization in sorghum. However, such bias is greatly reduced when a large number of technical and biological replicates are used. In this study, we used 5 individuals in three replicates.

\section{New sources of Striga resistance from the sorghum diversity panel}

Our findings underscore the need to continuously screen hosts for Striga resistance as affirmed by successful identification of new Striga resistant sorghum genotypes. The resistance by the genotypes, as determined by the number, size and biomass of Striga seedlings attached, is comparable to what has been reported in previous work that used rhizotrons [16, 21]. For example, we found an average of 57 attachments on N13 compared to a mean of 56 reported by [16] and 75 [22]. In a resistant rice variety (nipponbare) and maize (KSTP'94), parasite attachments averaged 30 [21] and 44 [23] respectively.

Overall, the rhizotron assay proved effective in screening the large number of sorghum lines for post-germination resistance to Striga. The metrics of resistance, in general correlated with each other. One can deduce that reduced number of attachments implies some pre-attachment mechanism while small parasites implies post-attachment mechanisms.

Rhizotron assays allowed us to identify a set of highly resistant sorghum genotypes that had considerably lower number of Striga attachments, length and biomass than known resistant controls. Some of these genotypes although found to be highly resistant to Striga are not grown in SSA. For example the Indian genotypes IS41724 (Advanced cultivar) and IS36633 (Breeding material) are good candidates for performance evaluation under Striga infestation in African agro-ecologies. Similarly, Striga resistant landraces IS21425 (Malawi); IS10971 (USA); IS14276 (South Africa) and IS22040 (India) can be evaluated for adaptability under Striga infestation. Finally, the resistant wild sorghum accessions IS18879 (USA) and IS14478 (Sudan) can be used a resistance source in genetic studies. Strikingly, out of a total of 206 sorghum accessions comprising 7 wild genotypes, 2 of wild sorghum accessions ranked among the best 10 performers. This underscores the importance of wild sorghum genotypes as a reservoir of disease resistance genes. Overall, integrating the Striga resistant varieties presented here in SSA breeding programs could complement Striga control efforts and contribute towards increasing yields due to reduced Striga infestation.

\section{Multiple mechanisms of Striga resistance}

We found that sorghum uses at least three resistance mechanisms to overcome Striga infection. Firstly, the physical barriers that successfully stop parasite ingression into host cells at either the cortex or the endodermis. Physical barrier resistance due to thickened cell walls and lignification, are well characterised in many Striga-host interactions and especially in N13; a resistant Indian Durra sorghum [15]. In the current study, we observed that IS10978 also exhibited this form of resistance. In rice, such a resistance mechanism was reported in some of the New Rice for Africa (NERICA) varieties [21]. Secondly, we observed an intense hypersensitive reaction at the host-parasite interface in IS14963. This 
response, reminiscent of gene-for-gene resistance described in the resistant cowpea variety (b301) against the hyper virulent $S$. gesnerioides race 3 from Niger (SG3) [24]. In sorghum, HR-kind-of resistance was described in the resistant genotypes Dobbs, Framida, and a wild sorghum genotype P47121 [17]. Finally, we observed a new resistance mechanism displayed by IS9830, in which Striga was unable to differentiate and form xylem vessels. Rather, the parasite went through the host root and exited without any attempt to make connections. This phenotype was only observed in IS9830. To our knowledge, such resistance has never been reported in any Striga-host interactions and although the molecular and physiological mechanisms underpinning this resistance are out of the scope of the current study, inability of parasite cells to differentiate and form vascular connections with the host appears to suggest that Striga is insensitive to the host's vascular differentiation signals.

\section{Genetic causes of Striga resistance}

Genetic loci associated with resistance corresponded with some Striga resistance quantitative trait loci (QTL) reported in [18], where 2 recombinant inbred lines (RILs) each based on pre-germination resistance (IS9830) and post-germination resistance (N13) parents were used to reveal 5 QTL each associated with Striga resistance. In our GWAS analysis, there were overlaps in QTL from both mapping populations on chromosomes 1, 2, 9 and 10. Interestingly QTL from the IS9830 RIL overlapped with significant SNPs in our GWAS analysis even though the genotype was used as a donor for pre-germination resistance. This observation reaffirms the hypothesis that IS9830 harbours both pre-germination and postgermination resistance as previously suggested [18].

In addition to QTL mapping, a recent study [19], performed genome-wide tests of association with predicted parasite habitat suitability (HS) in 2070 sorghum landraces and found 97 genomic regions associated with $S$. hermonthica resistance. There were no common SNPs between the current study and [19], plausibly because HS scores rely on Striga habitat distribution factors which can be too numerous to obscure specific components of post-germination resistance. Nonetheless general genes encoding similar mechanisms in cell wall modification, for example lignin biosynthesis were significantly associated with Striga resistance in both studies.

Based on significant associations in annotated genes, our study pointed to genetic processes leading to: i) synthesis and transport of secondary metabolites, ii) cell-wall modification and iii) activation of innate immunity.

We observed significant associations with ABCG/PDR transporter [25] as well as Isoflavon reductase [26] both of which are involved in secondary metabolites production and transport. In Striga, the PDR transporter was found to be significantly up regulated in the resistant rice cultivar (Nipponbare) following S. hermonthica infection [27]. Noteworthy, phytoalexins are primarily produced in leguminous plants [26] a fact that may explain their role non host incompatibility [28].

Our study also revealed Fasciclin-like arabinogalactan protein 11 involved in cell adhesion that form physical barriers against pathogen invasion [29] as well as secondary cell walls fortification encoding genes that use lignin deposition i.e. O-Methyltransferase (PMT) [30] and NAC domain transcription factor [31]. Both of these genes are involved in lignin biosynthesis and regulation, consistent with numerous studies that describe lignin as an important component in Striga resistance [32]. In addition to cell wall fortification, hosts may protect themselves against parasitic cell wall degrading enzymes such as a pectinesterases using their cognate inhibitors $[19,33]$. In this regard, our study revealed a gene encoding xylanase inhibitor 1. Possibly, this gene encodes a Striga xylanase inhibitor consistent with the gene's up-regulation in Striga-rice interactions [34].

Finally, consistent with the 'zigzag' model for Strigahost interactions [35], we identified genes encoding different components of pathogen activated immunity including: i) DNA repair and peroxidases; ii) DMR6 that participates in salicylic acid homeostasis and required for susceptibility to downy mildew in Arabidopsis [36] and $P$. infestans potato [37]; iii) and genes involved in induction of the Systemic Acquired Resistance (SAR) pathway which in Striga-rice interactions is regulated by both jasmonic acid (JA) and salycilic acid (SA) in a cross talk mediated by WRKY45 [38] and regulated by (AP2/ ERFs) [39]. Interestingly, AP2/ERFs were found to be significantly associated with $S$. hermonthica resistance in white [40] and yellow tropical maize [41]. These findings underscore the importance of this pathway in Striga resistance.

Although most of the SNPs identified can be implicated with Striga resistance, it is worth noting that in some cases, there were large genetic differences between SNPs and actual genes controlling the traits. Future studies should therefore investigate the identified genes in contrasting germplasm. Nonetheless, our work has paved the way for more targeted studies and even possible breeding targets.

In summary, sorghum harbors varied mechanisms of resistance to Striga. The genetic factors (loci) underpinning such mechanisms are distributed within the vast sorghum gene pool of wild and cultivated genotypes. This species "richness" - genetic diversity provides an important resource that should be exploited in future Striga resistance breeding programs. 


\section{Conclusions}

Taken together, we report on new sources of Striga resistant sorghum obtained from a diverse collection. We further elucidated mechanisms of post-attachment resistance in Striga. Our studies employed a controlled screening assay based on rhizotrons to obtain Striga resistance data that was subsequently used in GWAS. This assay provided a distinct advantage over previously used methods because it provided the opportunity to control for confounding environmental variability. We were thus able to in our GWAS and successfully identified gene regions that were significantly associated with Striga resistance. The method is widely applicable in postattachment resistance screening of other Striga-host interactions. Our study also led to identification of new Striga resistant sorghum varieties that can be directly integrated in sorghum improvement programs in SSA. Moreover, elucidation of new mechanisms of resistance will allow breeders to develop material with multiple forms of resistance for durable and broad-spectrum resistance while the identified resistance loci will accelerate the breeding process. This will have far reaching implications on Striga management programs in SSA. Finally, our study revealed associated with Striga resistance in sorghum. This finding is directly applicable in sorghum improvement programs for Striga resistance using marker assisted selection, genetic modification or modern gene-editing technologies.

\section{Methods}

\section{Plant material}

We used 206 sorghum genotypes of the Generation Challenge Program sorghum reference set (RS) (www. icrisat.org/what-we-do/crops/sorghum/Sorghum Reference.htm). The collection was originally obtained from the International Crops Research Institute for the Semi-Arid Tropics (ICRISAT) through their Nairobi, Kenya office. The organization maintains a vast repository for world sorghum that is well characterized and documented for ease of retrieval [42]. Detailed information on these genotypes is shown in (Table S1). The collection has been genotyped by sequencing [43] and SNP data is available at http://www.morrislab.org/data. This study used seeds of $S$. hermonthica from Western Kenya (Kisumu) located at $0.0699^{\circ} \mathrm{S}, 34.8169^{\circ} \mathrm{E}$ (Kibos isolate) harvested in 2012 and prepared as follows: Striga seed heads were collected from sorghum-infested farmer fields following approval and in accordance to regulations set by National Commission for Science, Technology and Innovation (NACOSTI). Harvested material was dried inside paper bags for 14 days. Heads containing Striga seeds were then threshed by lightly tapping the papers, and seeds separated from debris by passing through sieves with 250 and $150-\mu \mathrm{m}$ openings as previously described [44].

\section{Striga seed conditioning}

Striga seeds ( $25 \mathrm{mg}$ ) were surface sterilized using 10\% commercial bleach (v/v) containing sodium hypochlorite for $10 \mathrm{~min}$, followed by rinsing three times with sterile distilled water. The seeds were spread on filter papers (Whatman, GFA) placed inside a $90 \mathrm{~mm}$ Petri dish, then $5 \mathrm{ml}$ of sterile distilled water added to the plates. Plates were sealed with parafilm, wrapped in aluminum foil and incubated at $28{ }^{\circ} \mathrm{C}$ for 14 days. To induce germination, $3 \mathrm{ml}$ of filter-sterilized $0.1 \mathrm{ppm}$ GR24 (Chiralix, Amsterdam) was added and seeds incubated for $12 \mathrm{~h}$ at $28^{\circ} \mathrm{C}$. Striga seed viability was determined using a microscope (Leica MZ7F; Leica, Germany), and only plates with more than $70 \%$ efficiency used in infection of sorghum roots.

\section{Sorghum growth and infection with Striga}

We used a soil-free system, based on rhizotrons, to screen the sorghum lines for post-attachement resistance to Striga as previously described [16]. In this assay, resistance is measured by analyzing the mean number, lengths and total biomass of Striga seedlings attached on a host root. Successful colonization of a genotype by numerous and long Striga plants with a large biomass is interpreted as a susceptible response. In contrast, a resistance response is indicated by few, and short parasite seedlings with low Striga biomass.

The rhizotron assay was set up as follows: Sorghum seeds were germinated in plastic pots $(10 \times 10 \times 7 \mathrm{~cm})$ filled with vermiculite and watered with Long Ashton nutrient media [45]. Upon germination, seedlings were transferred to rhizotrons made from Petri plates measuring $25 \times 25 \times 5 \mathrm{~cm}$ (Nunc, Thermo Fisher Scientific, UK) prepared as follows: The base of the Petri plates was filled with vermiculite and the bottom lined with strips $(25 \times 4 \mathrm{~cm})$ of high density foam to absorb excess water. The plates were overlaid with a $50 \mu \mathrm{m}$-thick nylon mesh to separate vermiculite and plant roots, but allow access to nutrients. The lid was replaced and secured with insulating tape. The chambers were then wrapped with aluminium foil and maintained inside a glasshouse under a 12-h light/12-h dark photoperiod, $60 \%$ humidity with day and night temperatures of 28 and $24{ }^{\circ} \mathrm{C}$ for 10 days. During this period, the plants were drip-fed with Long Ashton plant nutrient media [45]. To infect sorghum roots with Striga, rhizotrons were opened and sorghum roots carefully aligned with $\sim 5000$ pre-germinated Striga seeds using a soft paint brush. After infection, the chambers were closed, wrapped in aluminum foil and maintained in the glasshouse as described above. Five 
plants per genotype were screened in a randomized complete block design (RCBD) in three replicates.

\section{Analysis of post-germination resistance of sorghum against Striga}

To identify sorghum genotypes resistant to $S$. hermonthica, we analyzed 3 metrics; number of Striga attachments on a host plant, length of the attached parasite seedlings and their biomass 21 days after infection (DAI). Striga seedlings attached to each host were harvested, placed in 90-mm Petri plates and photographed. We then used Image analysis software, ImageJ v.1.45 (http://rsb.info.nih.gov/ij) to determine length as well as the number of Striga seedlings per host plant. In addition, we determined Striga biomass after ovendrying the seedlings at $45^{\circ} \mathrm{C}$ for 7 days. We generated means and standard deviations for all three metrics, then carried out analysis of variance (ANOVA) using statistical analysis software (SAS v. 9.1, SAS Institute, Cary, NC, USA) for comparisons across genotypes. We then used the Tukey's honest significant difference (HSD) test $(p \leq 0.05)$ for mean separations and to assign groups to the genotypes based on resistance to Striga. Means of resistance for the top 50 resistant varieties for each metric were displayed as dot plots generated using the ggdotchart function in R.

To rank the resistance of sorghum genotypes in the diversity panel relative to known resistance controls i.e. IS9830 (an advanced cultivar of Caudatum race from East Africa) and an Indian Durra (N13, also annotated as IS18331 in some literature) we generated 5 categories of resistance. Genotypes with similar or significantly higher resistance than either N13 or IS9830 were grouped as "Highly Resistant", while those with one mean separation group less resistance than either IS9830 or N13 were considered "Resistant". Subsequent genotypes were categorized as "Moderately Resistant", "Susceptible" or "Highly Susceptible" based on decreasing classes on mean separations. Ochuti, a Striga-susceptible farmer-preferred landrace was used as a susceptible check. To better understand the metric that provided the best resolution of resistance variation among the sorghum genotypes, we subjected the 3 metrics to PC analysis.

To further determine the resistance response of sorghum accessions using the combined metrics of number of Striga attachments, length and biomass, we used the Rank Summation Index (RSI) originally described by described by [20] but modified by [11]. In the modification, accessions with high Striga resistance (low number of attachments, short length and low biomass) were assigned lower ranks while more susceptible ones were given lower ranks. The resulting RSI scores were used to produce a heatmap for the highest ranking 50 accessions using the $\mathrm{R}$ package pheatmap.

\section{Analysis of mechanisms of post-germination resistance against Striga}

Mechanisms of Striga resistance were evaluated in 20 accessions that displayed the lowest number of Striga attachments, the resistant controls (N13 and IS9830) and a highly susceptible accession (IS18829). These were done by analyzing the host-parasite interface, 9 days after infection (9DAI) through histological analysis. To achieve this, small sections of sorghum roots infected with S. hermonthica were excised, fixed in Carnoy's fixative $(4: 1,100 \%$ ethanol:acetic acid) and stained with $1 \%$ safranin in $30 \%$ ethanol for $5 \mathrm{~min}$. Tissues were then cleared with choral hydrate $(2.5 \mathrm{~g} / \mathrm{ml})$ for $12 \mathrm{~h}$ and the extent of parasite infection on the host roots documented using a Leica stereomicroscope MZ10F fitted with DFC 310FX camera.

Fixed tissue were then embedded by firstly preinfiltrating them in 1:1 parts Technovit ${ }^{\circ}$ solution (Haraeus Kulzer GmbH, Germany) and absolute ethanol for $2 \mathrm{~h}$ followed by infiltration in 100\% Technovit for $15 \mathrm{~min}$. The tissues were transferred to a fresh Technovit $^{\circ}$ solution and maintained for 3 days. To embed, tissue in upright position were placed in $1.5 \mathrm{ml}$ microcentrifuge lids containing 1 part Hardener ${ }^{\circ}$ and 15 parts Technovit ${ }^{\circ}$. After setting, embedded tissues were mounted onto wooden blocks using the Technovit ${ }^{\circ} 3040$ kit following the manufacturer's instructions (Haraeus Kulzer GmbH). For sectioning, we used the Leica RM 2145 microtome (Leica, Germany) to cut 5 - $\mu$ m-thick sections which were transferred onto glass slides dried on a hot plate at $65^{\circ} \mathrm{C}$ for $30 \mathrm{~min}$, stained using $0.1 \%$ toluidine blue $\mathrm{O}$ dye in $100 \mathrm{mM}$ phosphate buffer for 2 min and washed in distilled water. Dry slides were overlaid with cover slips using DePex (BDH, Poole, UK), observed, and photographed using a Leica DM100 microscope fitted with a Leica MC190 HD camera, (Leica, Germany).

\section{Population structure of the sorghum diversity panel}

To determine the hierarchical population structure of the sorghum reference panel, we subjected the SNP data to ADMIXTURE 1.3.0; a model-based software for estimation of ancestry in unrelated individuals using the maximum-likelihood method [46]. The analysis was performed for different clusters, referred to as $\mathrm{K}$, ranging from 1 to 10 (for 10 replications per $\mathrm{K}$ ). We then selected the most appropriate K-value based on the $\mathrm{K}$ that exhibited the lowest cross-validation error. To further elucidate genetic relationships among the sorghum germplasm, we converted the Hapmap genotype data, in Trait Analysis by aSSociation, 
Evolution and Linkage (TASSEL) to VCF format and used the resulting file to construct a neighbor-joining (NJ) tree using the Analyses of Phylogenetics and Evolution (APE) package in $R$ [47]. To visualize the global origin of various sorghum genotypes, we utilized the Geographical Positioning System (GPS) coordinates available at https://www.morrislab.org/data [48] to construct a distribution map using the maptools package in R. Finally, we employed the principal component analysis (PCA), using ggplot2 package in R [49] to understand the scattering and genetic relatedness of the sorghum diversity panel under this study.

\section{Genome wide association study}

Resistance data sets based on number of parasite attachments, length and biomass were used to identify SNPs associated with the resistance. Firstly, SNPs were filtered to only include those that had $>0.05$ allele frequency leaving 247,975 SNPs and 204 genotypes. We then carried in a GWAS utilizing the Fixed and random model Circulating Probability Unification FarmCPU [50] algorithm implemented in the Genomic Association and Prediction Integrated Tool (GAPIT) as described in [51]. Kinship (K) was calculated using the default parameters. Quantile - quantile and Manhattan plots were both generated outputs of GAPIT analysis. We used Q-Q plots to verify control for population structure and appropriateness of the association model and Manhattan plots to visualize SNPs that were significantly associated with Striga resistance. The threshold of association ( $p$-value) was determined for each trait using a false discovery rate (adjusted $p<0.05$ ) in GAPIT. All significant SNP markers were mapped onto the Sorghum bicolor v3.1.1 genome [52] in Phytozome v12.1 [53] using JBrowse [54] based on physical positions obtained during SNP calling.

\footnotetext{
Abbreviations

SSA: Sub-Saharan Africa; GWAS: Genome-wide association studies; GBS: Genotyping by sequencing; SNPs: Single Nucleotide Polymorphisms: Dmkr: Durra muskwaari; DC: Durra-caudatum; Gma: Guinea margaritiferum; RSI: Ranked summation index; NJ: Neighbour joining; CV: Cross Validation; PCA: Principal components analysis; DAl: Days after infection; HR: Hypersensitive reaction; FarmCPU: Fixed and random model Circulating Probability Unification; QQ: Quantile-Quantile; PDR: Pleiotropic drug resistance; ABC: ATP Binding Cassette; IFR: Isoflavon reductase; ERF: Ethyleneresponsive transcription factor; JA: Jasmonic acid; SA: Salicylic acid; Prx: Peroxiredoxin; NERICA: New Rice for Africa; SG3: Striga gesnerioides race 3; QTL: Quantitative trait loci; RILs: Recombinant inbred lines; SAR: Systemic Acquired Resistance; ICRISAT: International Crops Research Institute for the Semi-Arid Tropics; RCBD: Randomized complete block design;

ANOVA: Analysis of variance; HSD: Honest significant difference; TASSEL: Trait Analysis by aSSociation, Evolution and Linkage; GPS: Geographical Positioning System; GAPIT: Genomic Association and Prediction Integrated Tool; FDR: False Discovery Rate; NAC: NAM (No apical meristem); ATAF: Arabidopsis transcription activation factor; CUC: Cup-shaped cotyledon; ABCG/PDR: ATP binding cassette G/Pleiotropic drug resistance; AP2/ERFs: APETALA 2/Ethylene Responsive Factors; APE: Analysis of Phylogenetics and Evolution; VCF: Variant Call Format
}

\section{Supplementary Information}

The online version contains supplementary material available at https://doi. org/10.1186/s12870-021-03155-7.

\section{Additional file 1.}

Additional file 2.

Additional file 3.

Additional file 4.

\section{Acknowledgements}

We would like to acknowledge the International Crops Research Institute for the Semi-Arid Tropics (ICRISAT) through Dr. Eric Manyasa for availing the sorghum germplasm used in this project.

\section{Authors' contributions}

SR conceived and designed the study. JK, MK and IS performed Striga resistance screening experiments and GWAS guided by MW, TM and DO. WK carried out the histological analysis of Striga resistance mechanisms. JM and SM performed population structure analysis guided by SR. JK, SR, JM, and SM wrote the manuscript. All authors read and approved the final manuscript.

\section{Funding}

The National Research Fund (NRF) of Kenya supported data collection and analysis components of this work under the Multi Disciplinary Research Projects program (contract number KU/DVCR/NRF/NOL1/27). We further acknowledge writing and dissemination financial support provided by Kenyatta University through the Vice Chancellors Research grant number KU/ DVCRNRG/NOL.11/216. JK's PhD was supported by Regional Universities Forum for Capacity Building in Agriculture (RUFORUM) through a capacity building competitive grant (RU/2016/DRRG/01/010), NRF and an In-Country/ In-Region scholarship from the German Academic Exchange Service Deutscher Akademischer Austauschdienst (DAAD).

\section{Availability of data and materials}

All data generated or analyzed during this study are included in this published article and its supplementary information files.

\section{Declarations}

Ethics approval and consent to participate

Not applicable.

Consent for publication

Not applicable.

\section{Competing interests}

The authors declare that they have no competing interests.

\section{Author details}

'Department of Biochemistry, Microbiology and Biotechnology, Kenyatta University, Nairobi, Kenya. ${ }^{2}$ Pan African University of Science Technology and Innovation, Jomo Kenyatta University of Agriculture and Technology, Nairobi, Kenya. International Crops Research Institute for the Semi-Arid Tropics, Nairobi, Kenya.

Received: 4 August 2020 Accepted: 2 August 2021

Published online: 21 August 2021

References

1. Atera EA, Ishii T, Onyango JC, Itoh K, Azuma T. Striga infestation in Kenya: status, distribution and management options. Sustainable Agric Res. 2013; 2(2):99-108. https://doi.org/10.5539/sar.v2n2p99.

2. Ejeta G. The Striga scourge in Africa: a growing pandemic. In: Ejeta G, Gressel J, editors. Integrating New Technologies for Striga Control. Singapore: World Scientific Publishing Company; 2007. p. 3-16.

3. Kanampiu F, Makumbi D, Mageto E, Omanya G, Waruingi S, Musyoka P, et al. Assessment of management options on Striga infestation and maize grain yield in Kenya. Weed Sci. 2018;66(4):516-24. 
4. De Groote $H$, Wangare L, Kanampiu F, Odendo M, Diallo A, Karaya H, et al. The potential of a herbicide resistant maize technology for Striga control in Africa. Agric Syst. 2008;97(1):83-94.

5. Midega CAO, Salifu D, Bruce TJ, Pittchar J, Pickett JA, Khan ZR. Cumulative effects and economic benefits of intercropping maize with food legumes on Striga hermonthica infestation. Field Crop Res. 2014;155:144-52.

6. Ngugi K, Ngugi AJ, Osama S, Mugoya C. Combating Striga weed in sorghum by transferring resistance quantitative trait loci through molecular marker assisted introgression. J Plant Breed Genet. 2015;3(3):67-76.

7. Yohannes T, Abraha T, Kiambi D, Folkertsma R, Tom Hash C, Ngugi K, et al. Marker-assisted introgression improves Striga resistance in an Eritrean farmer-preferred Sorghum variety. Field Crop Res. 2015;173:22-9.

8. Hearne S. Control-the Striga conundrum. Pest Manag Sci. 2009;65:603-14.

9. Ejeta G. The Striga scourge in Africa: a growing pandemic. In: Gressel J, editor. Integrating new Technologies for Striga Control towards ending the witchhunt: Ejeta G. Singapore: World Scientific Publishing Company; 2007. p. 3-16.

10. Rich PJ, Ejeta G. Towards effective resistance to Striga in African maize. Plant Signal Behav. 2008;3(9):618-21.

11. Mallu TS, Mutinda S, Githiri SM, Odeny D, Runo S. New pre-attachment Striga resistant sorghum adapted to African agro-ecologies. Pest Manag Sci. 2021;77(6):2894-902

12. Hess DE, Ejeta G. Inheritance of resistance to Striga in Sorghum genotype SRN39. Plant Breed. 1992;109(3):233-41.

13. Gobena D, Shimels M, Rich PJ, Ruyter-Spira C, Bouwmeester H, Kanuganti S, et al. Mutation in sorghum LOW GERMINATION STIMULANT 1alters strigolactones and causes Striga resistance. Proc Natl Acad Sci. 2017;114(17):4471-6.

14. Rich PJ, Grenier C, Ejeta G. Striga resistance in the wild relatives of Sorghum. Crop Sci. 2004;44(6):2221-9.

15. Maiti RK, Ramaiah KV, Bisen SS, Chidley VL. A comparative study of the Haustorial development of Striga asiatica (L.) Kuntze on Sorghum cultivars. Ann Bot. 1984;54(4):447-57

16. Mbuvi DA, Masiga CW, Kuria E, Masanga J, Wamalwa M, Mohamed A, et al. Novel sources of Witchweed (Striga) resistance from wild Sorghum accessions. Front Plant Sci. 2017:8:116.

17. Mohamed A, Ellicott A, Housley TL, Ejeta G. Hypersensitive response to Striga infection in Sorghum. Crop Sci. 2003;43(4):1320-4.

18. Haussmann BIG, Hess DE, Omanya GO, Folkertsma RT, Reddy BVS, Kayentao $M$, et al. Genomic regions influencing resistance to the parasitic weed Striga hermonthica in two recombinant inbred populations of sorghum. Theor Appl Genet. 2004;109(5):1005-16.

19. Bellis ES, Kelly EA, Lorts CM, Gao H, DeLeo VL, Rouhan G, et al. Genomics of sorghum local adaptation to a parasitic plant. Proc Natl Acad Sci. 2020;117(8):4243-51.

20. Mulamba M. Improvement of Yield Potential of the Eto Blanco Maize (Zea mays L.) Population by Breeding for Plant Traits. Egyptian J Genet Cytol. 1978;1:40-51.

21. Cissoko M, Boisnard A, Rodenburg J, Press MC, Scholes JD. New Rice for Africa (NERICA) cultivars exhibit different levels of post-attachment resistance against the parasitic weeds Striga hermonthica and Striga asiatica. New Phytol. 2011;192(4):952-63.

22. Pescott O. The Genetics of Host Adaptation in the Parasitic Plant Striga hermonthica. PhD thesis: University of Sheffield, Department of Animal \& Plant Sciences; 2013

23. Mutinda SM, Masanga J, Mutuku JM, Runo S, Alakonya A. KSTP 94, an openpollinated maize variety has Postattachment resistance to purple Witchweed (Striga hermonthica). Weed Sci. 2018;66(4):525-9.

24. Li J, Timko MP. Gene-for-gene resistance in Striga-cowpea associations. Science. 2009;325(5944):1094

25. He $Y, X u$ J, Wang $X$, He $X$, Wang $Y$, Zhou J, et al. The Arabidopsis pleiotropic drug resistance transporters PEN3 and PDR12 mediate Camalexin secretion for resistance to Botrytis cinerea. Plant Cell. 2019;31(9):2206.

26. Banks SW, Dewick PM. Biosynthesis of glyceollins I, II and III in soybean. Phytochemistry. 1983;22(12):2729-33.

27. Swarbrick PJ, Scholes JD, Press MC, Slate J. A major QTL for resistance of rice to the parasitic plant Striga hermonthica is not dependent on genetic background. Pest Manag Sci. 2009;65(5):528-32.

28. Hiraoka Y, Ueda H, YSJOE b. 2009: molecular responses of Lotus japonicus to parasitism by the compatible species Orobanche aegyptiaca and the incompatible species Striga hermonthica. J Exp Bot. 2009;60(2):641-50.

29. Bonazzi M, Cossart P. Impenetrable barriers or entry portals? The role of cell-cell adhesion during infection. J Cell Biol. 2011;195(3):349-58.

30. Guo D, Chen F, Inoue K, Blount JW, Dixon RA. Downregulation of caffeic acid 3-O-methyltransferase and caffeoyl CoA 3-O-methyltransferase in transgenic alfalfa: impacts on lignin structure and implications for the biosynthesis of $\mathrm{G}$ and S lignin. Plant Cell. 2001;13(1):73.

31. Golfier P, Volkert C, He F, Rausch T, Wolf S. Regulation of secondary Cell Wall biosynthesis by a NAC transcription factor from Miscanthus. Plant Direct. 2017;1(5):e00024.

32. Mutuku JM, Cui S, Hori C, Takeda Y, Tobimatsu Y, Nakabayashi R, et al. The structural integrity of lignin is crucial for resistance against Striga hermonthica parasitism in Rice. Plant Physiol. 2019;179(4):1796.

33. Yang Z, Wafula EK, Honaas LA, Zhang H, Das M, Fernandez-Aparicio M, et al. Comparative transcriptome analyses reveal core parasitism genes and suggest gene duplication and repurposing as sources of structural novelty. Mol Biol Evol. 2015;32(3):767-90.

34. Swarbrick PJ, Huang K, Liu G, Slate J, Press MC, Scholes JD. Global patterns of gene expression in rice cultivars undergoing a susceptible or resistant interaction with the parasitic plant Striga hermonthica. New Phytol. 2008;179(2):515-29.

35. Timko MP, Huang K, Lis KE. Host resistance and parasite virulence in Striga-host plant interactions: A shifting balance of power. Weed Sci. 2012:60(2):307-15.

36. Van Damme M, Huibers RP, Elberse J, Van den Ackerveken G. Arabidopsis DMR6 encodes a putative 2OG-Fe (II) oxygenase that is defense-associated but required for susceptibility to downy mildew. Plant J John Wiley \& Sons, Ltd (101111). 2008;54:785-93.

37. Sun $\mathrm{K}$, Wolters $\mathrm{A}$, Vossen J, Rouwet $\mathrm{M}$, Loonen $\mathrm{A}$, Jacobsen $\mathrm{E}$, et al. Silencing of six susceptibility genes results in potato late blight resistance. Transgenic Res. 2016;25(5):731-42

38. Mutuku JM, Yoshida S, Shimizu T, Ichihashi Y, Wakatake T, Takahashi A, et al. The WRKY45-dependent signaling pathway is required for resistance against Striga hermonthica parasitism. Plant Physiol. 2015;168(3):1152-63.

39. Licausi F, Ohme-Takagi M, Perata P. APETALA2/ethylene responsive factor (AP2/ERF) transcription factors: mediators of stress responses and developmental programs. New Phytol. 2013;199(3):639-49.

40. Adewale SA, Badu-Apraku B, Akinwale RO, Paterne AA, Gedil M, GarciaOliveira AL. Genome-wide association study of Striga resistance in early maturing white tropical maize inbred lines. BMC Plant Biol. 2020;20(1):203.

41. Badu-Apraku B, Adewale S, Paterne A, Gedil M, Asiedu R. Identification of QTLs controlling resistance/tolerance to Striga hermonthica in an extra-early maturing yellow maize population. Agronomy. 2020;10:873.

42. Reddy VG, Upadhyaya HD, Gowda CLL. Current status of Sorghum genetic resources at ICRISAT: their sharing and impacts. oar.icrisat.org. 2006.

43. Morris GP, Ramu P, Deshpande SP, Hash CT, Shah T, Upadhyaya HD, et al. Population genomic and genome-wide association studies of agroclimatic traits in sorghum. Proc National Acad Sci. 2013;110(2):453-8.

44. Berner DK, Winslow MD, Awad AE, Cardwell KF, Mohan Raj DR, Kim SK. Striga research methods: A manual. The Pan-African Striga Control Network (PASCON). Ibadan: IITA; 1997

45. Hudson JP. Sand and water culture methods used in the study of plant nutrition. Exp Agric. 1967;3(2):104

46. Alexander DH, Novembre J, Lange K. Fast model-based estimation of ancestry in unrelated individuals. Genome Res. 2009;19(9):1655-64.

47. Paradis E, Claude J, Strimmer K. APE: analyses of Phylogenetics and evolution in R language. Bioinformatics. 2004;20(2):289-90.

48. Lasky JR, Upadhyaya HD, Ramu P, Deshpande S, Hash CT, Bonnette J, et al. Genome-environment associations in sorghum landraces predict adaptive traits. Sci Adv. 2015;1(6):e1400218.

49. Wickham H. ggplot2: Elegant Graphics for Data Analysis, vol. 16; 2016

50. Liu X, Huang M, fan B, Buckler ES, Zhang Z. Iterative usage of fixed and random effect models for powerful and efficient genome-wide association studies. PLoS Genet. 2016:12(2):e1005767.

51. Lipka AE, Tian F, Wang Q, Peiffer J, Li M, Bradbury PJ, et al. GAPIT: genome association and prediction integrated tool. Bioinformatics. 2012;28(18):2397-9.

52. McCormick RF, Truong SK, Sreedasyam A, Jenkins J, Shu S, Sims D, et al. The Sorghum bicolor reference genome: improved assembly, gene annotations, a transcriptome atlas, and signatures of genome organization. Plant J. 2018;93(2):338-54.

53. Goodstein DM, Shu S, Howson R, Neupane R, Hayes RD, Fazo J, et al. Phytozome: a comparative platform for green plant genomics. Nucleic Acids Res. 2012;40(Database issue):D1178-86.

54. Skinner ME, Uzilov AV, Stein LD, Mungall CJ, Holmes IH. JBrowse: a nextgeneration genome browser. Genome Res. 2009;19(9):1630-8.

\section{Publisher's Note}

Springer Nature remains neutral with regard to jurisdictional claims in published maps and institutional affiliations. 